\title{
RESENHA -
}

PANKE, Luciana. Lula, do sindicalismo à reeleição - um caso de comunicação política e discurso. Guarapuava: Unicentro; São Paulo: Horizonte, 2010; 216 p.

Lucas Gandin ${ }^{1}$

Taiana L. Bubniak ${ }^{2}$

"Lula nasceu pobre, em Pernambuco. E criança veio para São Paulo. Tornou-se líder sindical, foi preso pela ditadura e fundou o PT. Lula se tornou o primeiro operário presidente e deu rumo ao Brasil. (...) Lula está encerrando o mandato como o melhor presidente da nossa história. Inovou, rompeu barreiras, mudou o país" (ROUSSEFF, HGPE, 17/08/10). Foram com essas palavras que o programa eleitoral de Dilma Rousseff apresentou uma pequena biografia do então presidente Luiz Inácio Lula da Silva; história de um personagem que se confunde com os relatos sobre a política brasileiros pós-redemocratização. Lula esteve presente em todos os processos eleitorais depois da redemocratização do Brasil. Em 1989, 1994, 1998, 2002 e 2006, participou como candidato ao cargo de presidente da República, sendo derrotado nos três primeiros pleitos, vencendo o quarto e foi reeleito no quinto. Antes disso, militou como líder sindical de 1968 a 1980 e foi deputado federal de 1987 a 1989. Nas eleições de 2010, a presença de Lula também foi marcante. No entanto, desta vez não disputava cargo como candidato, sua presença serviu de cabo-eleitoral para a candidata do seu partido, Dilma Rousseff.

Da década de 1960 (início da atividade sindical) para cá, Lula proferiu inúmeros discursos e é sobre esse vasto material que se debruçam os estudos e as análises da professora da Universidade Federal do Paraná, Luciana Panke, contidos no livro Lula, do sindicalismo à reeleição - um caso de comunicação política e discurso (Editoras Unicentro e Horizonte, 216 p.). Já na apresentação do livro, a autora invoca um saber notório, o de que não se faz política sem discurso. No entanto, ela vai mais além, explicando que este espaço de fala constitui uma das razões para a propagação de

\footnotetext{
${ }^{1}$ Jornalista, Relações Públicas e mestrando do programa de Pós-Graduação em Comunicação e Sociedade da Universidade Federal do Paraná. Bolsistas Reuni.

${ }_{2}^{2}$ Jornalista, especialista em comunicação política e mestranda do programa de Pós-Graduação em Comunicação e Sociedade da Universidade Federal do Paraná. Bolsista Reuni.
} 
ideologias e para a luta simbólica pelo poder. O livro, fruto da tese de doutoramento de Panke, defendida em 2005 na Escola de Comunicação e Artes da Universidade de São Paulo, buscou demonstrar o "valor da palavra como uma manifestação políticoideológica por excelência" (p. 20).

Para isso, a análise dos discursos de Lula engloba pronunciamentos realizados por ele durante sua vida pública, acompanhando os períodos de sindicalista, deputado federal, candidato à Presidência e presidente da República, compreendendo mais de 30 anos de trajetória política. Diante de um corpus extenso, foi escolhida a temática do emprego e trabalho como recorte. A autora parte da hipótese de que, ao longo desses quase trinta anos, o teor dos discursos de Lula teria mudado radicalmente à medida em quem ele galgava os cargos políticos eletivos, mas que isso não teria ocorrido apenas em 2002. A pesquisa de fato compra a hipótese: Panke (2010) classifica a fala de Lula em três fases: a da extrema esquerda (1968 a 1989), quando os discursos são mais agressivos, oposicionistas e radicais, versando contra o capital, o governo e a favor da liberdade expressão; a fase de transição (década de 90), na qual Lula, líder do Partido dos Trabalhadores - PT e candidato nas eleições de 1994 e 1998, reformula seu posicionamento e passa a projetar imagem e discurso mais conciliador, visando ao diálogo; e a fase de centro esquerda (eleição de 2002 e 2006), em que Lula evidencia discurso mais amadurecido e imagem requintada, resultando numa forma de expressão mais suave e que garante sua vitória em ambos os pleitos.

Como metodologia de análise, Panke (2010) utiliza análise do discurso de vertente francesa os postulados da Teoria da Argumentação de Perelman e OlbrechtsTyteca. No que tange à Análise do Discurso, este é entendido como "um efeito de sentido construído pela articulação de processos ideológicos, fenômenos linguísticos e não linguísticos" (PANKE, 2010, p. 29). Nesse sentido, o discurso político se configura como uma manifestação linguística sobre o espaço público, em questões relacionadas à vida social, buscando a alteração da ordem vigente, e à projeção de um futuro. Segundo a autora, a Teoria da Argumentação leva em conta o fato de que o discurso político utiliza a razão e a emoção em sua materialização linguística. Quando voltado à razão, o orador provar sua tese, recorrendo a dados estatísticos e informações lógicas. Se voltado à emoção, o orador, sem poder provar sua tese, acorda-a com o auditório, fazendo uso do seu conhecimento empírico comum ao deste para provocar anuência. 
De acordo com o estudo de Panke (2010), na primeira fase de seus discursos extrema esquerda - Lula recorre ao uso de analogias, metáforas e comparações para simplificar as ideias e suscitar valores fundamentais, como a crença, a fé, a certeza e o patriotismo. Nessa fase, o ex-presidente adquire a consciência da situação do trabalhador e da dinâmica sindical. O leitor poderá conferir que seus discursos são mais informais, pendendo à oralidade, com expressões populares da língua portuguesa. Também é difícil diferenciar quando Lula reforça seu caráter, por meio de expressões como "eu vou fazer", "eu vou lutar" ou quando ele conclama os trabalhadores a se unirem à causa: "sentimos na própria carne" (em referência à exploração capitalista do trabalhador); "o Partido dos Trabalhadores nasceu dos que nunca tiveram vez e voz na sociedade brasileira" (p. 73).

Nessa fase também se acentua o simbolismo da imagem do herói em torno de Lula, que personifica a esperança o início de tempos melhores. É nesse momento que ele se apresenta como líder do povo. No período em que foi deputado federal, as críticas à política econômica e à ideologia dos poderes econômico, político e midiático continuam, assim como o intenso uso da palavra "desemprego" em seus discursos. Já na década de 90, Lula entra numa fase de transição ideológica e aos poucos se torna mais ameno, embora as críticas à política econômica, ao aumento do desemprego e às privatizações e à entrada de capital estrangeiro persistam. Por outro lado, a possibilidade de análise de acordos com credores internacionais para o pagamento da dívida externa começa e a apresentação de propostas para sanar a questão do desemprego evidenciam uma tentativa de Lula desfazer a imagem de radical.

É a fase intitulada por Panke (2010) como centro-esquerda, quando Lula tornou seu discurso mais aprazível a um público mais abrangente. O ápice deste formato do discurso pode ser observado, de acordo com a autora, na campanha presidencial de 2002, a empreitada vitoriosa de Lula e seu grupo político. As mudanças de posicionamento ideológico ocorridas durante a década de 1990 contribuíram para a formação do discurso bem-sucedido do então candidato. Portanto, esta campanha é considerada "sui generis".

O primeiro fato que demonstra estas mudanças é a formação da coligação que concorreria ao Executivo nacional: pela primeira vez, o Partido dos Trabalhadores congregou grupos políticos de direita, como o Partido Liberal (PL). Outra característica marcante é a contratação do publicitário Duda Mendonça, que tinha como desafio 
transformar a opinião pública, que acreditava que o PT e o candidato Lula poderiam ser danosos para o país.

Para enfrentar tais tarefas, estratégias imagéticas e discursivas foram utilizadas. Durante a exibição do HGPE, ao invés de jargões de esquerda e tom agressivo sobre o sistema produtivo adotado na maioria dos países, Lula estava em um grande escritório, personificando a imagem de um administrador bem-sucedido. Mesmo com ênfase no candidato, os símbolos do PT - a estrela e objetos na cor vermelha - estavam presentes, reforçando essa ligação simbólica.

Entre os principais motes do discurso, estava a transformação de uma imagem do candidato e do grupo político relacionada à briga e desordem para um discurso que refletisse alívio e esperança, para que não houvesse "medo de ser feliz", como indicava um dos jingles da campanha. O público ampliou-se e temas como o aumento do consumo, antes recriminada, passaram a ser tratados como prioridade.

No segundo turno das eleições, disputado, na ocasião com o candidato José Serra, do PSDB, foi mantida a tática de reconstruir a imagem do candidato perante a população. Desta forma, Lula foi indicado como conciliador e única alternativa para um país mais justo. Assim, na quinta disputa ao cargo de presidente do Brasil, Lula recebeu mais de $60 \%$ dos votos e confirmou a vitória.

A partir da chegada ao cargo, manteve-se o discurso da fase centro-esquerda. Panke (2010) recolheu uma amostragem de 261 discursos proferidos no primeiro ano de governo, em 2003. Destes, 53\% abordavam a temática escolhida. Agora presidente, Lula engendra um discurso que busca, de início, reafirmar a identidade ideológica do PT, salientando que seu governo seria um governo do povo. A formalidade nos discursos se torna mais presente, sempre aliada a referências numéricas e estatísticas e dividindo espaço com argumentos emocionais e valores. Novamente, Lula conclama todos para resolver o problema da falta de emprego no país. Seu discurso lança mão de recursos estilísticos tais quais frases de efeito como "olhem nos meus olhos", "chance de vencer na vida", e distinção de gênero para criar empatia e comoção no público.

A autora inclui uma fala de Lula em Dantas ${ }^{3}$ que pode oferecer explicações para a mudança no tom dos discursos ao longo do período analisado:

${ }^{3}$ DANTAS, A. JR. Lula sem censura. 3 ed. Petrópolis: Vozes, 1981. 
ao entrar no sindicato me deparei com um fato muito engraçado: você sai do campo teórico e entra no campo prático. Quando a gente não é do sindicato, sempre responsabiliza os diretores por não resolverem os problemas. (PANKE, 2010, p. 64).

O excerto evidencia que a experiência adquirida é um importante fator para mudanças de postura e, no caso de Lula, elas se refletem no discurso. De um modo geral, o livro apresenta um importante levantamento sobre o discurso político e consegue oferecer dados para compreensão de sua dinâmica inclusive para outros personagens.

A reeleição de Lula também foi um caso emblemático. Diante de altos índices de aprovação - mesmo em meio a denúncias de corrupção por parte de integrantes do alto escalão do governo - a estratégia de campanha em 2006 no primeiro turno girou em torno dos feitos governamentais e das possibilidades de expansão do que já estava sendo colocado em prática. E os discursos da campanha eleitoral analisados mostraram que a temática emprego, alicerçada a questões sociais, se manteve presente em todo o corpus da pesquisa.

Buscou-se manter a imagem de homem forma na liderança do Estado e também os elementos de ligação com o público, indicando elementos de identificação, como o uso de expressões coloquiais e da palavra "povo". A manutenção de programas do governo, como o Bolsa-Família, também foi temática constante. Lula manteve idéias semelhantes ao pleito anterior e fez promessas ligadas à geração de emprego e conseqüente aumento do poder de compra e da qualidade de vida da população.

O final do primeiro turno e segundo turno, de acordo com a pesquisa, aponta-se uma utilização maior de elementos comparativos entre o governo Lula e de seu antecessor, Fernando Henrique Cardoso, que esteve na presidência entre 1995 e 2003. Os programas veiculados no HGPE mostram que a campanha de Lula e de Geraldo Alckmin (PSDB), mantinha um diálogo, pois ataques adversários eram rebatidos neste espaço.

As características do discurso proferido nesta campanha também levam a crer, de acordo com a autora, que houve uma personalização mais acentuada da figura de Lula. Se em 2002, mesmo com a mudança do tom agressivo para o aprazível, mantinham-se as cores e símbolo do partido, quatro anos depois se buscou enfatizar as cores da bandeira brasileira, o que remete ao nacionalismo. 
Desde o início da vida política até ser eleito pela segunda vez como presidente da República, as falas proferidas por Lula mostraram quem era e quais eram os objetivos dele como representante do povo. O livro mostra essas mudanças e o porquê destes acontecimentos; o sistema eleitoral, o público, os eleitores e as mudanças de posicionamento ideológico do grupo político parecem ter influenciado as diferenciações. Ao final do livro, um quadro sintético condensa as principais características de cada fase dos discursos de Lula, oferecendo um panorama histórico e global do estudo desenvolvido por Panke (2010).

Lula não foi o primeiro e nem o único a mesclar razão e emoção, a proferir discursos fortes, que estabeleceram empatia e carisma no público, pois estas características são inerentes ao discurso político. Contudo, é o nosso exemplo mais próximo. Se pudéssemos comparar seus discursos com os de Getúlio Vargas e Jucelino Kubitschek, veríamos que Lula tem a vantagem de ainda estar na cena política e seu caso não é algo do passado; se faz presente. É nesse contexto que Lula, do sindicalismo à reeleição, se faz um livro atual, que auxilia a compreensão sobre as características sobre a vida política do país, além da relevância do discurso político como baliza das ações do público, constituído por possíveis eleitores.

A presente obra interessa a todos que buscam entender as relações entre comunicação e política. A afinidade entre elas é capaz de influenciar de forma contundente no modelo de sistema representativo que está presente na maioria dos países de regimes democráticos e particularmente, no recente caso brasileiro, destrinchado de forma didática e clara neste livro. 